\title{
Electrocardiogram and Echocardiographic Findings of COVID-19 Patients in Makati Medical Center
}

\author{
Maria Kristina Cecilia P. Ozaeta, M.D, FPCP, ${ }^{1}$ Frances Dianne M. Dela Cruz, M.D, ${ }^{1}$ Maria Cristina A. Sombrero, M.D, FPCP, ${ }^{1}$ \\ Kristine Karla N. Estuita, M.D, ${ }^{1}$ Valerie Zarza-Geron, M.D, FPCP, FPCC, ${ }^{1}$ Paul C. Quetua, M.D, FPCP, FPCC, ${ }^{1}$ Gilbert G. \\ Florentino, M.D, FPCP, FPCC, ${ }^{1}$ Saturnino P. Javier, M.D, FPCP, FPCC ${ }^{1}$ \\ Section of Cardiology, Makati Medical Center, Philippines
}

Main author: Maria Kristina Cecilia P. Ozaeta

Affiliation: Section of Cardiology, Makati Medical Center, Philippines

Contact information: kristina_ozaeta@yahoo.com

\section{ABSTRACT}

\section{BACKGROUND}

Echocardiography and electrocardiogram may prove useful in the care of COVID-19 patients but there is limited data postulating their usefulness in this disease.

\section{OBJECTIVE}

To determine electrocardiographic and echocardiographic findings among COVID-19 patients in Makati Medical Center

\section{METHODS}

A retrospective single center analytical study involving adult Reverse transcription polymerase chain reaction (RT-PCR) confirmed COVID-19 positive patients admitted in Makati Medical Center from March to April 16, 2020. These patients had more than one electrocardiogram (ECG) result and a 2D echocardiography done during their admission. The initial and repeat ECGs during the course of hospital stay were obtained to determine if there were changes in ECG. On the other hand, echocardiographic investigations were confined to studies of left and right ventricular systolic function.

\section{RESULTS}

In the initial ECG findings, the most common abnormalities observed were QT prolongation (39.39\%), ischemic changes $(15.15 \%)$, and fascicular blocks (12.12\%). During the course of admission, the most common were still QT prolongation (39.39\%) and ischemic changes (13.64\%), with the additional observation of further prolongation in QT from baseline (24.24\%). For the echocardiographic findings, the right and left systolic functions were preserved in majority of the patients. No significant difference was noted in the electrogram and echocardiographic findings between survivor and non-survivors.

\section{CONCLUSION}

Majority of patients had abnormal ECG at baseline with further worsening during the course of confinement. Almost all abnormalities were related to QT prolongation. Though most patients had elevated cardiac biomarkers, only few patients had notable abnormalities in left and right ventricular function.

\section{Keywords}

COVID 19, Electrocardiogram, 2D Echocardiography

\section{INTRODUCTION}

In late 2019, a group of patients presenting with pneumonia in Wuhan, China heralded the outset of COVID-19. SARSCoV2, the virus that causes COVID-19, not only causes viral pneumonia but has major implications for the cardiovascular (CV) system. According to the ESC Guidance for the Diagnosis and Management of CV Disease during the COVID-19 Pandemic, the cardiovascular involvement may be due to the binding of SARS-CoV2 to the host receptor angiotensin-converting enzyme 2 (ACE2) to mediate entry into cells. The ACE2 is expressed in the lungs, heart and vessels and is a key member of the renin angiotensin system (RAS) which is important in the pathophysiology of cardiovascular disease. ${ }^{1}$ It has been postulated that this illness can cause vessel thrombosis, myocarditis and arrhythmias. Thus, echocardiography and electrocardiogram may be useful in the care of patients of COVID-19

Several studies reported transient occurrence of S1Q3T3, complete AV blocks and ST segment elevation in patients with COVID-19 infection. ${ }^{2}$ Other studies reported unmasking or complicating preexisting arrhythmias such as Brugada Syndrome, ${ }^{3,4}$ and inherited arrhythmia syndromes (Long QT syndrome, short QT syndrome, Catecholaminergic Polymorphic Ventricular Tachycardia). ${ }^{4}$ Moreover, there has been reported development of ventricular arrhythmias such as Torsades de Pointes with the use of Azithromycin and Hydroxychloroquine, drugs use as treatment for COVID-19. ${ }^{5}$

Myocarditis and heart failure are well-recognized cardiovascular complications of respiratory infection during previous historical epidemics such as Middle East respiratory syndrome (MERS) and severe acute respiratory syndrome (SARS). ${ }^{6}$ The viral infection may contribute to the instability of chronic cardiovascular disease mainly due to an imbalance between the increase in viral-induced metabolic demand and limited cardiac reserve. In patients with pre-existing cardiovascular diseases, the severity of the primary respiratory syndrome and risk of adverse outcomes is increased. Previous studies on SARS patients also suggest that left ventricular performance was subclinically impaired during the acute phase of the infection and that it may be reversible on clinical recovery. ${ }^{7}$ Yu et al reported that reversible cardiomegaly may be present but without evidence of heart failure. ${ }^{8}$ Previous studies have demonstrated that cytokine-mediated systemic response to infections can cause a reduction in left and right ventricular ejection fraction with increased end-diastolic and end-systolic 
volumes. It is still unknown whether this is holds true in COVID-19. ${ }^{9}$

Despite the above findings, there is limited data postulating the usefulness of electrocardiogram and 2D echocardiography in the management of COVID-19. The main objective of this investigation was to determine electrocardiographic and echocardiographic findings among COVID-19 patients in Makati Medical Center. Specifically, the study aimed the following:

1. To evaluate changes in ECG findings, compared from the initial ECG, of COVID-19 patients during the course of their admission.

2. To identify the types of arrhythmias that frequently occur in patients with COVID-19

3. To assess left and right ventricular systolic function by specific 2D echocardiographic parameters among COVID patients.

4. To compare electrocardiographic and echocardiographic findings between non-survivor and survivor COVID-19 patients.

\section{METHODS}

\section{STUDY DESIGN}

This was a retrospective single center analytical study involving adult COVID positive patients admitted in Makati Medical Center from March to April 16, 2020. We reviewed the electronic medical records and hospital charts of all patients who were COVID-19 RT-PCR positive during the said duration of the study

\section{STUDY POPULATION}

A total of 66 patients were included in the study. The population included all adult patients (ages 18 and above) admitted at Makati Medical Center from the month of March until April 16, 2020 with positive COVID-19 test, more than one electrocardiogram result and a 2D echocardiography done during their admission.

\section{DATA COLLECTION AND ANALYSIS}

The 12-Lead electrocardiogram taken initially and during the course of hospital stay were obtained to determine changes in the electrocardiogram. An electrocardiogram with changes from the baseline (i.e. QT prolongation, ischemic changes, further prolongation of QT, atrioventricular blocks) during the course of confinement were considered as abnormal.

For the 2D Echocardiography part, heart function was evaluated for the right and left systolic function. For left ventricular systolic function, different parameters were compared such as left ventricular volume, left ventricular dimension, cardiac output (CO), left ventricular ejection fraction (LVEF), systolic index of contractility (dP/dt), global longitudinal strain (GLS) with speckle tracking echocardiography (STE). On the other hand, for right ventricular systolic function, the following parameters were measured: Right ventricular dimension, wall thickness, Tricuspid annular plane systolic excursion (TAPSE), 2D Right Ventricular Fractional Area of Change (RV FAC), systolic pulmonary arterial pressure (SPAP), and septal dyskinesia. In addition, there could also be presence of thrombus formation (Parameters for normal echocardiographic findings and abnormal electrocardiographic findings were defined in the Definition of Terms portion of this paper).

\section{Figure 1: Method of data collection}

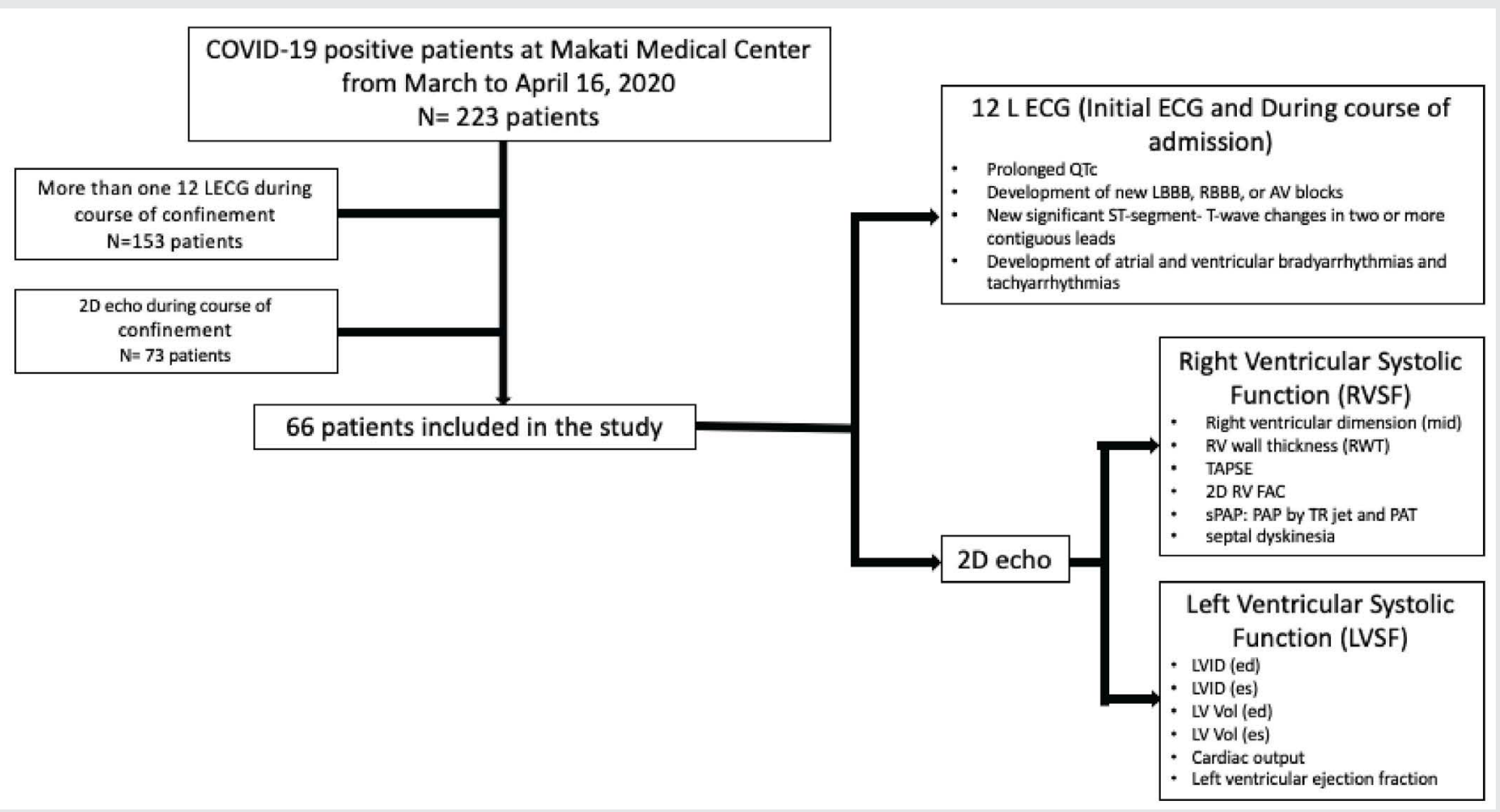


Descriptive statistics was used to summarize the general and clinical characteristics of the participants. Frequency and proportion were used for categorical variables. Shapiro-Wilk test was used to determine the normality distribution of continuous variables. Continuous quantitative data that met the normality assumption was summarized using mean and standard deviation (SD), while those that do not was described using median and range.

Independent T-test was used to determine the difference of mean continuous variables between non-ICU and ICU patients. Continuous variables which are not normally distributed were compared using the non-parametric Mann-Whitney $U$ test.

For categorical variables, Chi-square test was used to compare the outcomes. If the expected percentages in the cells are less than 5\%, Fisher's Exact test was used instead.

Odds ratios and corresponding its 95\% confidence intervals were computed using binary and exact logistic regression. All valid data was included in the analysis. Missing variables was neither replaced nor estimated. Null hypothesis was rejected at 0.05a-level of significance. STATA 15.0 was used for data analysis.

\section{RESULTS}

This study analyzed a total of 66 patients diagnosed with COVID-19. Their mean $( \pm S D)$ age at $59.08( \pm 12.2)$, and more than half were male [68.18\%]. As shown in Table 1, more than half [70\%] were hypertensive, while 25 [38\%] were diabetic. Twenty-one [31.82\%] developed shock and 46 [69.7\%] had Acute respiratory Distress Syndrome (ARDS) determined by PF ratio in ABG. Mortality rate of this group of patients was $16.67 \%$ (Table 1).

Among those with cardiac biomarker assays, troponin was elevated in 18 [47\%], CPK 22 [76\%], and CKMB 7 [25\%].

Initial ECG findings (Table 3) showed that the most common ECG abnormalities observed were QT prolongation 26 [39\%], ischemic changes 10 [15\%], and fascicular blocks 7 [11\%]. During the course of admission, the most common were still QT prolongation 26 [39\%] and ischemic changes 9 [14\%], with the additional observation of further prolongation in QT from baseline in 16 [24\%].

\section{Figure 2: Initial ECG findings on admission and during the clinical course}

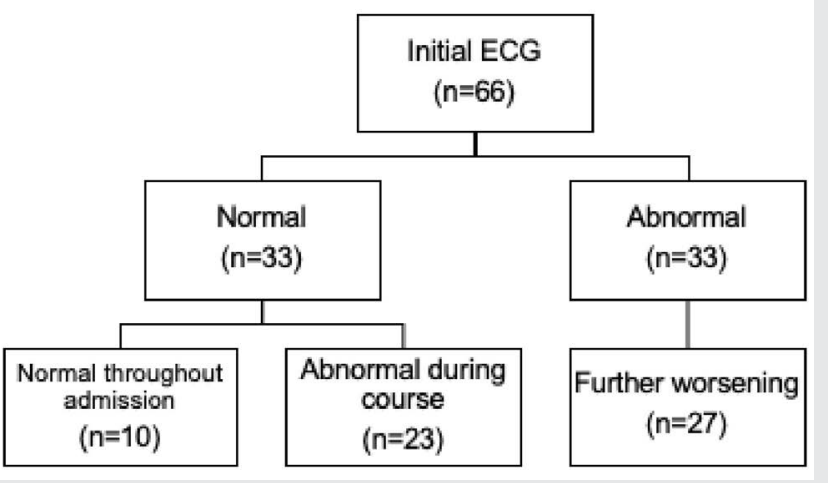

\begin{tabular}{lc}
\hline $\begin{array}{l}\text { Table } \mathbf{1 .} \text { Demographic and clinical characteristics of COVID-19 } \\
\text { patients }(\mathbf{n}=\mathbf{6 6})\end{array}$ & Mean \pm SD; Frequency (\%) \\
& $59.08 \pm 12.20$ \\
\hline Age & \\
\hline Sex & $45(68.18)$ \\
Male & $21(31.82)$ \\
Female & $12(18.18)$ \\
\hline Smoking & $4.5(0.15-30)$ \\
\hline Pack-years & \\
\hline Comorbidities & $46(69.70)$ \\
Hypertension & $6(9.09)$ \\
CAD & $25(37.88)$ \\
DM Type 2 & $2(3.03)$ \\
COPD & $8(12.12)$ \\
CKD & $1(1.52)$ \\
CA & $11(16.67)$ \\
\hline Others & $21(31.82)$ \\
\hline Shock & $46(69.70)$ \\
\hline ARDS & \\
\hline Chest X-ray findings & $3(4.55)$ \\
No infiltrates & $56(84.85)$ \\
Pneumonia & $3(3.4 .55)$ \\
Congestion & $4(6.06)$ \\
Pleural effusion & $5(7.58)$ \\
\hline Cardiomegaly & \\
\hline Level of care & $39(59.09)$ \\
Non-ICU & $27(40.91)$ \\
\hline ICU & \\
\hline Outcome & $55(83.33)$ \\
Alive & $11(16.67)$ \\
Mortality & $13.95 \pm 8.7$ \\
\hline Length of admission, days & \\
\hline & \\
\hline
\end{tabular}

\begin{tabular}{lcc}
\hline \multicolumn{2}{l}{ Table 2. Cardiac biomarkers of COVID-19 patients } & \\
& Median (Range) & Abnormal \\
\cline { 2 - 3 } & & Frequency (\%) \\
\hline Troponin I $[n=38]$ & $0.012(0.001-6.16)$ & $18(47.37)$ \\
\hline CPK $[n=29]$ & $190.51(0.2-11183.14)$ & $22(75.86)$ \\
\hline CKMB $[n=28]$ & $1.15(0.1-498.7)$ & $7(25)$
\end{tabular}

\begin{tabular}{|c|c|c|}
\hline & Initial ECG & $\begin{array}{l}\text { ECG during course } \\
\text { of admission }\end{array}$ \\
\hline QT prolongation & 26 (39.39) & 26 (39.39) \\
\hline $\begin{array}{l}\text { Further prolongation in QT } \\
\text { from baseline }\end{array}$ & - & $16(24.24)$ \\
\hline Ischemic changes & $10(15.15)$ & $9(13.64)$ \\
\hline Brugada pattern & 0 & $1(1.52)$ \\
\hline Fascicular blocks & $7(10.61)$ & $8(12.12)$ \\
\hline First degree AV block & $1(1.52)$ & 0 \\
\hline Bundle branch blocks & $2(3.03)$ & $5(7.58)$ \\
\hline
\end{tabular}




\begin{tabular}{lcc}
\hline \multicolumn{3}{l}{ Table 4. 2D Echo findings of COVID-19 patients, RVSF $(\mathbf{n}=\mathbf{6 6})$} \\
& $\begin{array}{c}\text { Mean } \pm \text { SD; } \\
\text { Median (Range) }\end{array}$ & $\begin{array}{c}\text { Abnormal } \\
\text { Rrequency (\%) }\end{array}$ \\
\hline Right ventricular dimension (mid) & $2.92 \pm 0.36$ & $1(1.52)$ \\
\hline RV wall thickness & $0.41 \pm 0.07$ & $27(40.91)$ \\
\hline TAPSE & $20(17-30)$ & 0 \\
\hline 2D RV FAC & $51.86 \pm 9.73$ & $1(1.52)$ \\
\hline SPAP & & \\
\multicolumn{1}{c}{ TR jet $[n=39]$} & $24.59 \pm 7.85$ & $3(7.69)$ \\
PAT $[n=45]$ & $126(88-164)$ & $5(11.11)$ \\
\hline
\end{tabular}

Septal dyskinesia

In terms of right ventricular systolic function (RVSF) (Table 4), abnormal values were noted in 27 [40.91\%] patients as to Right Ventricular (RV) wall thickness, while pulmonary hypertension, seen as elevated Tricuspid regurgitation (TR jet), was noted in three [7.69\%] patients and prolonged Pulmonary Acceleration Time (PAT) in five [11.11\%] patients.

The subgroup analysis for those with ARDS are in Table 4.1.

Among those with ARDS, the most common abnormal echo finding was RV wall thickness in $24(52.17 \%)$ patients (Table 4.1)

The most common echocardiographic findings related to left ventricular systolic function (LVSF) (Table 5) were abnormalities in Left Ventricular end diastolic volume LV volume (LVEDV) in 10 [15\%], followed by cardiac output 9 [14\%], and Left Ventricular internal diameter in end diastole (LVID ed) in 8 [12\%]. Moreover, there were eight [12\%] with abnormal wall motion, seven [11\%] with segmental hypokinesia, and one [1.52\%] had global hypokinesia (Table 6). Two [3\%] of patients have abnormalities in ejection fraction and only nine [53\%] patients had abnormal global longitudinal strain (Table 6)

\begin{tabular}{|c|c|c|}
\hline & \multirow{2}{*}{$\begin{array}{c}\text { Mean } \pm \text { SD; } \\
\text { Median (Range) }\end{array}$} & \multirow{2}{*}{$\begin{array}{c}\text { Abnormal } \\
\text { Frequency (\%) }\end{array}$} \\
\hline & & \\
\hline Right ventricular dimension (mid) & $2.93 \pm 0.36$ & $1(2.17)$ \\
\hline RV wall thickness & $0.42 \pm 0.07$ & $24(52.17)$ \\
\hline TAPSE & $20(17-30)$ & 0 \\
\hline 2D RV FAC & $51.22 \pm 9.62$ & $1(2.17)$ \\
\hline \multicolumn{3}{|l|}{ sPAP } \\
\hline TR jet $[n=26]$ & $24.96 \pm 8.88$ & $3(11.54)$ \\
\hline PAT [n=34] & $126(91-164)$ & $4(11.76)$ \\
\hline
\end{tabular}

Septal dyskinesia

\begin{tabular}{|c|c|c|c|c|}
\hline & Overall $(n=66)$ & Male $(n=45)$ & Female $(n=21)$ & Abnormal \\
\hline \multicolumn{4}{|c|}{ Mean \pm SD; Median (Range) } & Frequency (\%) \\
\hline LVID (ed) & $4.64 \pm 0.49$ & $4.71 \pm 0.40$ & $4.49 \pm 0.64$ & $8(12.12)$ \\
\hline LVID (es) & $3.02 \pm 0.47$ & $3.07 \pm 0.44$ & $2.90 \pm 0.52$ & $7(10.61)$ \\
\hline LV vol (ed) & $100.95 \pm 24.49$ & $104 \pm 20.67$ & $94.43 \pm 30.72$ & $10(15.15)$ \\
\hline LV vol (es) & $33(13-78)$ & $36(15-72)$ & $29(13-78)$ & $8(12.12)$ \\
\hline LV EF (Teicholz) & $65(40-77)$ & $65(46-77)$ & $66(40-77)$ & $3(4.55)$ \\
\hline LV EF (Simpsons) & $65(42-73)$ & $64(50-77)$ & $66(42-73)$ & $2(3.03)$ \\
\hline Cardiac output & $5.29 \pm 1.40$ & $5.55 \pm 1.15$ & $4.72 \pm 1.72$ & $9(13.64)$ \\
\hline
\end{tabular}

Normal values: LVID (ed) - 3.8 to 5.2 (F) and 4.2 to 5.8 (M): LVID(es) -2.2 to 3.5 (F) and 2.5 to 4.0 (M): LV vol (ed) - 46 to 106 (F) and 62 to 150 (M); LV vol (es) - 14 to 42 (F) and 21 to 61 (M); LV ef - $\geq 54$ (F) and $\geq 52(\mathrm{M})$; and $\mathrm{CO}-\geq 4$

\begin{tabular}{|c|c|}
\hline \multicolumn{2}{|c|}{ Table 6. 2D Echo findings in COVID-19 inpatients $(n=66)$} \\
\hline & Median (Range); Frequency (\%) \\
\hline Global longitudinal strain $[n=17]$ & $-18(-22.5$ to -0.0017$)$ \\
\hline Normal & $8(47.06)$ \\
\hline Abnormal & $9(52.94)$ \\
\hline Thrombus & 0 \\
\hline \multicolumn{2}{|l|}{ Wall motion } \\
\hline Normal & $58(87.88)$ \\
\hline Abnormal & $8(12.12)$ \\
\hline \multicolumn{2}{|l|}{ Hypokinesia } \\
\hline Global & $1(1.52)$ \\
\hline Segmental & $7(10.61)$ \\
\hline
\end{tabular}

\begin{tabular}{|c|c|c|c|c|c|c|}
\hline & Non-critical $(n=39)$ & Critical $(n=27)$ & $p$ & Non-critical $(n=39)$ & Critical $(n=27)$ & $p^{\neq}$ \\
\hline & \multirow{2}{*}{\multicolumn{3}{|c|}{ Mean \pm SD; Median (Range) }} & \multicolumn{3}{|l|}{ Abnormal } \\
\hline & & & & Frequency (\%) & & \\
\hline \multicolumn{7}{|l|}{ RVSF } \\
\hline Right ventricular dimension (mid) & $2.94 \pm 0.32$ & $2.87 \pm 0.41$ & 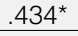 & 0 & $1(3.70)$ & .409 \\
\hline $\mathrm{RV}$ wall thickness & $0.41 \pm 0.07$ & $0.41 \pm 0.06$ & $.983^{*}$ & $16(41.03)$ & $11(40.74)$ & .982 \\
\hline TAPSE & $21(17-30)$ & $19(17-23)$ & $.014^{\dagger}$ & 0 & 0 & - \\
\hline 2D RV FAC & $52 \pm 10.4$ & $51.67 \pm 8.86$ & $.892^{*}$ & $1(2.56)$ & 0 & .402 \\
\hline sPAP TR jet [n=39] & $24.67 \pm 6.66 ;[n=24]$ & $24.47 \pm 9.71 ;[n=15]$ & $.940^{\star}$ & $2(8.33)$ & $1(6.67)$ & .849 \\
\hline PAT $[n=45]$ & $126(88-164) ;[n=25]$ & $125(91-152) ;[n=20]$ & $.622^{\dagger}$ & $3(12)$ & $2(10)$ & .832 \\
\hline Septal dyskinesia & 0 & 0 & - & 0 & 0 & - \\
\hline \multicolumn{7}{|l|}{ LVSF } \\
\hline LVID (ed) & $4.73 \pm 0.46$ & $4.51 \pm 0.51$ & $.073^{*}$ & $4(10.26)$ & $4(14.81)$ & .707 \\
\hline LVID (es) & $3.1 \pm 0.48$ & $2.90 \pm 0.42$ & $.081^{*}$ & $5(12.82)$ & $2(7.41)$ & .691 \\
\hline LV vol (ed) & $105.36 \pm 24.38$ & $94.59 \pm 23.65$ & $.079^{*}$ & $5(12.82)$ & $5(18.52)$ & .729 \\
\hline LV vol (es) & $36(18-78)$ & $32(13-53)$ & $.167^{\dagger}$ & $6(15.38)$ & $2(7.41)$ & .455 \\
\hline LV EF (Teicholz) & $65(40-77)$ & $65(49-75)$ & $.754^{\dagger}$ & $2(5.13)$ & $1(3.70)$ & .1 .000 \\
\hline LV EF (Simpsons) & $64(42-77)$ & $65(53-74)$ & $.467^{\dagger}$ & $2(5.13)$ & 0 & .509 \\
\hline Cardiac output & $5.34 \pm 1.47$ & $5.21 \pm 1.31$ & $.707^{*}$ & $6(15.38)$ & $3(11.11)$ & .727 \\
\hline
\end{tabular}

Statistical Tests Used: * - Independent t-test; $\uparrow$ - Mann Whitney U test; $\ddagger$ - Fisher's Exact test/Chi-square test 
On the other hand, comparing 2D Echo findings of COVID-19 critical and noncritical patients, there was no statistically significant differences between non-critical and critical groups in LVSF parameters. For RVSF parameters, only TAPSE had significant difference, $p=0.014$, however, it should be noted that even though there was significant difference between the two groups, both still had normal results. When comparing the proportion of patients who had abnormal values, these groups did not have any statistically significant difference. In both groups, 11 [41\%] had abnormal RV wall thickness. LVSF parameters were abnormal in less than $20 \%$ of the patients in both groups (Table 7 )

Among 39 non-critical patients, there were only 11 in whom global longitudinal strain was obtained. Five patients had abnormal global longitudinal strain. There were six non-critical patients with abnormal wall motion. Global hypokinesia was seen in one patient, and segmental hypokinesia was seen in five patients. Mild pulmonary hypertension was reported in five, or $12.82 \%$, of the non-critical patients.

Among 27 critical patients, there were only six patients in whom global longitudinal strain was recorded. Four patients had abnormal global longitudinal strain. There were two critical patients with abnormal wall motion. Segmental hypokinesia was seen in two patients. None had pulmonary hypertension.

Exact logistic regression was perform ed to determine the association between clinical factors with mortality in COVID-19. Among the baseline characteristics and comorbidities, none was found to have a significant association to mortality. All 11 mortalities have had shock and ARDS, which was significantly high compared to 10 [18.18\%] and 35 [63.64\%] among survivors (Table 9).

\section{DISCUSSION}

\section{ELECTROCARDIOGRAM FINDINGS OF COVID-19 PATIENTS}

In the initial ECG, majority of patients had already prolonged $\mathrm{QT}$, followed by ischemic changes and fascicular blocks. A great number of patients developed abnormalities in succeeding ECGs with development of new QT prolongation, further prolongation in QT from baseline, ischemic changes and fascicular blocks. Most of mortality [90.91\%] in our study had ECG abnormalities namely

\begin{tabular}{|c|c|c|c|}
\hline & Non-critical $(n=39)$ & Critical $(n=27)$ & $p$ \\
\hline & \multicolumn{2}{|c|}{ Median (Range); Frequency (\%) } & \\
\hline Global longitudinal strain & {$[n=11]$} & {$[n=6]$} & \\
\hline$[n=17]$ & $-18(-22.5$ to -0.0017$)$ & $-0.177(-0.26$ to -0.11$)$ & $.724^{\dagger}$ \\
\hline Normal & $6(54.55)$ & $2(33.33)$ & $.620^{\ddagger}$ \\
\hline Abnormal & $5(45.45)$ & $4(66.67)$ & \\
\hline Thrombus & 0 & 0 & - \\
\hline Wall motion & & & $.455^{\ddagger}$ \\
\hline Normal & $33(84.62)$ & 25 (92.59) & \\
\hline Abnormal & $6(15.38)$ & $2(7.41)$ & \\
\hline \multicolumn{4}{|l|}{ Hypokinesia } \\
\hline Global & $1(2.56)$ & 0 & $1.000^{\ddagger}$ \\
\hline Segmental & $5(12.82)$ & $2(7.41)$ & $.691^{\ddagger}$ \\
\hline Pulmonary hypertension & & & $.073^{\ddagger}$ \\
\hline Normal & $34(87.18)$ & $27(100)$ & \\
\hline Mild & $5(12.82)$ & 0 & \\
\hline Moderate & 0 & 0 & \\
\hline Severe & 0 & 0 & \\
\hline
\end{tabular}

Statistical Tests Used: † - Mann Whitney U test; $¥$ - Fisher’s Exact test/Chi-square test

\begin{tabular}{|c|c|c|c|c|}
\hline & Mortality $(n=11)$ & Survivor $(n=55)$ & $\begin{array}{l}\text { Crude Odds Ratio } \\
(95 \% \mathrm{Cl})\end{array}$ & $p$ \\
\hline Age & $61 \pm 9.65$ & $58.69 \pm 12.69$ & $1.016(0.96-1.07)$ & .565 \\
\hline \multicolumn{5}{|l|}{ Sex } \\
\hline Male & $8(72.73)$ & $37(67.27)$ & $1.297(0.31-5.48)$ & .723 \\
\hline Female & $3(27.27)$ & 18 (32.73) & Reference & - \\
\hline Smoking & $2(18.18)$ & $10(18.18)$ & $1(0.19-5.36)$ & 1.00 \\
\hline Pack-years & $9.5(6-13)$ & $2(0.15-30)$ & & \\
\hline \multicolumn{5}{|l|}{ Comorbidities } \\
\hline Hypertension & $7(63.64)$ & 39 (70.91) & $0.718(0.18-2.80)$ & .633 \\
\hline CAD & $1(9.09)$ & 5 (9.09) & $1(0.11-9.51)$ & 1.00 \\
\hline DM Type 2 & $4(36.36)$ & $21(38.18)$ & $0.925(0.24-3.55)$ & .910 \\
\hline COPD & $1(9.09)$ & $1(1.82)$ & $5.4(0.31-93.61)$ & .247 \\
\hline CKD & $1(9.09)$ & $7(12.73)$ & $0.686(0.08-6.21)$ & .737 \\
\hline $\mathrm{CA}$ & 0 & $1(1.82)$ & $5(0-195)$ & 1.00 \\
\hline Others & $3(27.27)$ & $8(14.55)$ & $2.203(0.48-10.11)$ & .310 \\
\hline Shock & $11(100)$ & $10(18.18)$ & $60.966(8.93-\operatorname{lnf})$ & $<.001$ \\
\hline ARDS & $11(100)$ & $35(63.64)$ & $8.347(1.25-\operatorname{lnf})$ & .025 \\
\hline \multicolumn{5}{|l|}{ Chest $X$-ray findings } \\
\hline No infiltrates & 0 & $3(5.45)$ & $1.281(0-12.64)$ & 1.00 \\
\hline Pneumonia & $11(100)$ & 45 (81.82) & $3.222(0.46-\operatorname{Inf})$ & .277 \\
\hline Congestion & $1(9.09)$ & $2(3.64)$ & $2.65(0.22-32.08)$ & .444 \\
\hline Pleural effusion & 0 & $4(7.27)$ & $0.981(0-7.94)$ & .946 \\
\hline Cardiomegaly & $2(18.18)$ & $3(5.45)$ & $3.852(0.56-26.38)$ & .170 \\
\hline $\begin{array}{l}\text { Abnormal/Elevated } \\
\text { Troponin I [n=38] }\end{array}$ & $5(50)[n=10]$ & $\begin{array}{c}13(46.43) \\
{[n=28]}\end{array}$ & $1.154(0.27-4.89)$ & .846 \\
\hline $\begin{array}{l}\text { Abnormal/Elevated CPK } \\
{[n=29]}\end{array}$ & 6 (85.71); [n=7] & $\begin{array}{c}16(72.73) \\
{[n=22]}\end{array}$ & $2.25(0.22-22.79)$ & .492 \\
\hline $\begin{array}{l}\text { Abnormal/Elevated } \\
\text { CKMB }[n=28]\end{array}$ & $3(50) ;[n=6]$ & $\begin{array}{c}4(18.18) \\
{[n=22]}\end{array}$ & $4.5(0.65-31.08)$ & .127 \\
\hline Abnormal ECG & $10(90.91)$ & 38 (69.09) & $4.474(0.53-37.78)$ & .169 \\
\hline Abnormal 2D Echo & $1(9.09)$ & $11(20)$ & $0.4(0.05-3.47)$ & .406 \\
\hline $\begin{array}{l}\text { Pulmonary } \\
\text { hypertension, mild }\end{array}$ & $1(9.09)$ & $4(7.27)$ & $1.275(0.13-12.64)$ & .836 \\
\hline
\end{tabular}


QT prolongation, ischemic changes, fascicular blocks, bundle branch blocks and one ECG showing Brugada pattern.

In the study by McCullough et. al, they performed a retrospective cohort study in patients with COVID-19 who had an ECG at or near hospital admission. Clinical characteristics and ECG variables were obtained from the health record and first ECG where the primary outcome was death. Presence of atrial premature contractions (APCs), repolarization abnormalities, a right bundle branch block (RBBB) or intraventricular block and ischemic $T$ wave changes increased the odds of death. This study was able to explain the probable cause of Right Bundle Branch blocks which could be attributed to acute right ventricular overload and distention in pulmonary embolism. ${ }^{10}$ The said ECG changes were also seen in our study present during baseline ECG and even developing during the course of admission. However, this was also observed among survivors.

What is striking in this study is the presence of QT prolongation during their first recorded ECG and even worsening of QT prolongation in majority of the patients during the course of admission. It should be taken into consideration that this initial ECG may already reflect some degree of treatment. This finding could be attributed to the use of antimalarials and antivirals that is used in the treatment of this disease. In the study of Mercuco et. al. and Chorin et. al., patients who received hydroxychloroquine for the treatment of COVID-19 were at high risk of QTc prolongation, and concurrent treatment with azithromycin was associated with greater changes in QTc ${ }^{11,12}$ with one patient developing Torsades de Pointes requiring cardioversion. ${ }^{12}$

One patient included in the study was noted to have Brugada pattern on ECG which was not present during admission. Chang et. al. presented a case of a COVID-19 infection unmasking Brugada syndrome. COVID-19 infection is typified by fever, a known precipitant of arrhythmia in patients with Brugada syndrome. Uncontrolled fever in patients with Brugada syndrome portends higher risk for syncope and sudden cardiac arrest. ${ }^{3}$ The increase in the body temperature has been proven to cause a higher degree of inactivation of $\mathrm{Na}+$ channels. This reduced $\mathrm{Na}+$ flow can result into a dangerous transmural heterogeneity which is the basis for phase 2 reentry ventricular arrhythmias and sudden death. ${ }^{13}$ Patient with this finding may warrant more aggressive antipyretic therapy.

\section{ECHOCARDIOGRAPHY FINDINGS OF COVID-19 PATIENTS}

Findings in our study showed that left ventricular systolic function are preserved in majority of the patients. Results of right ventricular function were also mostly normal even among patients in whom ARDS was identified (only one patient had an abnormal RVFAC). Even though difference was observed in the TAPSE between critical and non-critical patients, results are still both normal. In the present literatures reviewed, inconsistent data with regards to abnormalities in $2 \mathrm{D}$ echo were found. Findings could be normal, predominance of right ventricular dysfunction, predominance of left ventricular dysfunction or both.

In a study done by Szekely et. al., it was seen that among patients with abnormal echocardiogram at presentation, systolic left ventricular dysfunction was uncommon, observed in less than $10 \%$. The most frequent abnormality was RV dilation with or without dysfunction, possibly related to pulmonary parenchymal or vascular disease. ${ }^{14}$ Another study by Sud et. al. showed regional LV dysfunction appears to be the most common echocardiographic finding, suggesting that ischemia due to large- or small-vessel obstruction and prothrombotic state may be a common mechanism of injury. ${ }^{15}$

The reported results of Dweck, M. et al. was the first international survey of echocardiography in patients with confirmed or suspected COVID-19. Patient undergoing echocardiography had clearly defined clinical indications of performing such evaluation (i.e. suspected left or right sided heart failure, chest pain with STsegment elevation on the electrocardiogram, cardiac biomarker elevation [troponin or brain natriuretic peptide (BNP)], ventricular arrhythmia, suspected tamponade or cardiogenic shock). This study demonstrated left or right ventricular abnormalities in half of all patients with COVID-19 undergoing echocardiography, and that these abnormalities were severe in 1 of 7 patients. The majority had non-specific patterns of ventricular dysfunction, although new myocardial infarction, myocarditis, and takotsubo cardiomyopathy were observed in a minority of patients.

Echocardiography was reported to directly change patient management in a third of cases including alterations to diseasespecific management, hemodynamic support, and the level of care received by the patients. ${ }^{16}$

Furthermore, almost all patients who died had abnormal ECGs. Only one mortality had an abnormal echocardiography result. Still, no significant difference was noted in both electrocardiogram and echocardiographic findings between survivor and non-survivors. While all mortalities in this study had ARDS and shock, abnormalities in ECG and 2D echo, reflecting cardiac involvement, may not have implications in survival. Death from the said disease could mainly be due to the acute lung injury and the severe inflammatory response thereby secondarily affecting the heart by increasing the cardiac workload. Focusing on improving the ventilation and circulation of patient may probably improve disease outcomes.

One of the limitations of this research is its small sample size. Most patients included in the study had only one $2 \mathrm{D}$ echo result. Not all patients had cardiac biomarkers, 12 L ECG and 2D echo because during the data gathering period of this study, there was still evolving knowledge about COVID treatment and the needed ancillaries. It would be better if more data will be reviewed and added to this research with serial examinations of ECG and 2D echo done as baseline and during the varying severity if the illness. Also, future research could investigate correlation of abnormalities in 2D echo with regards to co-morbidities of the patient.

This study supports the recommendation of ESC to avoid performing routine transthoracic echocardiography in which test results are unlikely to change the management strategy. Moreover, findings regarding the prevalence of QT prolongation should alert physicians on the risk of developing drug-induced torsades de pointes and sudden cardiac death thereby validating the importance of correcting electrolytes and avoiding drugs that could prolong the QT interval if not necessary. A clear indication of why an ECG and echocardiogram is being done could lessen risk exposure of health care workers, conserve personal protective equipment, and appropriately allocate resources of our patients. 


\section{CONCLUSION}

This study showed that COVID-19 can have cardiovascular involvement as seen in the abnormalities manifested in the electrocardiogram and 2D echocardiography result of patients. Majority had abnormal ECG during admission with further worsening during the course of confinement. Almost all abnormalities were related to QT prolongation. Though most patients had elevated in cardiac biomarkers, only few patients had notable abnormalities in left and right ventricular function.

\section{APPENDIX}

\section{DEFINITION OF TERMS:}

\section{Right ventricular systolic function defined by the following parameters:}

- Right ventricular dimension (mid): $1.9-3.5 \mathrm{~cm}$

- RV wall thickness (RWT): 0.22 to $0.42 \mathrm{~cm}$

- TAPSE - greater than or equal to $17 \mathrm{~mm}$

- 2D RV FAC: greater than or equal to $35 \%$

- sPAP: PAP by TR jet - less than $36 \mathrm{mmHg}$, by PAT - more than $110 \mathrm{msec}$.

- Absence of septal dyskinesia.

\section{Left ventricular systolic function defined by the following parameters}

- LVID (ed) Male 4.2-5.8 cm, Female $3.8-5.2 \mathrm{~cm}$

- LVID (es) Male 2.5- $4.0 \mathrm{~cm}$

- LV Vol (ed) Male 62-150 ml

- LV Vol (es) Male21-61 ml, female 14-42 ml

- Cardiac output: > $4 \mathrm{~L} / \mathrm{min}$

- Left ventricular ejection fraction: male $>52 \%$, female $>54 \%$

- Systolic index of contractility $>1200 \mathrm{mmHg} / \mathrm{s}$

- Global longitudinal strain: -18 to $-22 \mathrm{mmHg}$

\section{Abnormal ECG findings defined by the following parameters:}

- Prolonged QTc defined as more than $450 \mathrm{msec}$ in males, and more than 460 msec in females

- Development of new left bundle branch block (LBBB), right bundle branch block (RBBB), or Atrioventricular blocks

- Development of atrial and ventricular bradyarrhythmia and tachyarrhythmia

- New significant ST-segment- T-wave changes in two or more contiguous leads:

o ST elevation at the $\mathrm{J}$ point $\geq 0.1 \mathrm{mV}$ in all leads other than leads $\mathrm{V} 2$ and $\mathrm{V} 3$ where the following cut points apply: $\geq 0.2 \mathrm{mV}$ in men $\geq 40$ years; $0.25 \mathrm{mV}$ in men $<40$ years, or $\geq 0.15 \mathrm{mV}$ in women.

o ST depression horizontal or down-sloping $\geq 0.05 \mathrm{mV}$; or $\mathrm{T}$ wave inversion $\geq 0.1 \mathrm{mV}$ with prominent $\mathrm{R}$ wave or $\mathrm{R} / \mathrm{S}$ ratio $\geq 1$

o New ECG changes indicative of trans-mural infarction $(Q$ wave in leads V2 and V3 $\geq 0.02 \mathrm{sec}$ or QS complex in leads V2 and V3; $Q$ wave $\geq 0.03 \mathrm{sec}$ and $\geq 0.1 \mathrm{mV}$ deep or QS complex in leads I, II, aVL, aVF or V4-V6 in any two leads of a contiguous lead grouping [lateral - I and aVL; precordial - V1-V6; infero-posterior - II, III, aVF] or $R$ wave $\geq 0.04$ sec in $V 1$ and $V 2$ and $R / S \geq 1$ with a concordant positive $T$ wave) in the absence of conduction abnormalities

\section{REFERENCES}

1. The European Society for Cardiology. ESC Guidance for the Diagnosis and Management of CV Disease during the COVID-19 Pandemic. https:// www.escardio.org/Education/COVID-19-and-Cardiology/ESC- COVID-19Guidance. (Last update: 10 June 2020)

2. He J, Wu B, Chen Y, Tang J, Liu Q, Zhou S, Chen C, Qin Q, Huang K, Lv J, Chen Y, Peng D, Characteristic ECG Manifestations in Patients with COVID-19, Canadian Journal of Cardiology (2020), doi: https://doi. org/10.1016/j.cjca.2020.03.028

3. Chang D, Saleh M, Garcia-Bengo Y, Choi E, Epstein L, Willner J, COVID-19 Infection Unmasking Brugada Syndrome, Heart Rhythm Case Reports (2020), doi: https:// doi.org/10.1016/j.hrcr.2020.03.012

4. Wu C-I, Postema PG, Arbelo E, Behr ER, Bezzina CR, Napolitano C, Robyns T, Probst V, Schulze-Bahr E, Remme CA, Wilde AAM, SARS-CoV-2, COVID-19 and inherited arrhythmia syndromes, Heart Rhythm (2020), doi: https://doi.org/10.1016/j.hrthm.2020.03.024.

5. Simpson, T.F, Kovacs, R.J., Stecker, E.C. (2020). Ventricular arrhythmia risk due to hydroxychloroquine-azithromycin treatment for COVID-19. American College of Cardiology.

6. Driggin E, Madhavan MV, Bikdeli B, Chuich T, Laracy J, Bondi-Zoccai G, Brown TS, Nigoghossian CD, Zidar DA, Haythe J, Brodie D, Beckman JA, Kirtane AJ, Stone GW, Krumholz HM, Parikh SA, Cardiovascular Considerations for Patients, Health Care Workers, and Health Systems During the Coronavirus Disease 2019 (COVID-19) Pandemic, Journal of the American College of Cardiology (2020), doi: https://doi.org/10.1016/j. jacc.2020.03.031.

7. Li SS et al. Left ventricular performance in patients with severe acute respiratory syndrome: a 30-day echocardiographic follow up study. Circulation 2003;108:1798-1803.

8. Yu C. et al. Cardiovascular complications of severe acute respiratory syndrome. Postgrad Med J 200;82:140-144

9. Tian Yuan Xiong. Coronavirus and the cardiovascular system: acute and long-term implications. European Heart Journal, ehaa231, 18 March 2020.

10. McCullough, S. A., Goyal, P., Krishnan, U., Choi, J. J., Safford, M. M., \& Okin, P. M. (2020). Electrocardiographic Findings in Coronavirus Disease-19: Insights on Mortality and Underlying Myocardial Processes. Journal of Cardiac Failure. https://doi.org/10.1016/j.cardfail.2020.06.005

11. Mercuro NJ, Yen CF, Shim DJ, et al. Risk of QT Interval Prolongation Associated With Use of Hydroxychloroquine With or Without Concomitant Azithromycin Among Hospitalized Patients Testing Positive for Coronavirus Disease 2019 (COVID-19). JAMA Cardiol. Published online May 01, 2020. doi:10.1001/jamacardio.2020.1834

12. Chorin E, Wadhwani L, Magnani S, Dai M, Shulman E, Nadeau-Routhier C, Knotts R, Bar-Cohen R, Kogan E, Barbhaiya C, Aizer A, Holmes D, Bernstein S, Spinelli M, Park DS, Stefano C, Chinitz LA, Jankelson L. QT interval prolongation and torsade de pointes in patients with COVID-19 treated with hydroxychloroquine/azithromycin. Heart Rhythm. 2020 May 12:S1547-5271(20)30435-5. doi: 10.1016/j.hrthm.2020.05.014. Epub ahead of print. PMID: 32407884; PMCID: PMC7214283.

13. Sorgente A, Capulzini L, Brugada $P$, The Known into the Unknown: Brugada syndrome and COVID-19, JACC Case Reports (2020), doi: https://doi.org/10.1016/j.jaccas.2020.04.006.

14. Szekely, Y., Lichter, Y., Taieb, P., Banai, A., Hochstadt, A., Merdler, I., Gal Oz, A., Rothschild, E., Baruch, G., Peri, Y., Arbel, Y., \& Topilsky, Y. (2020). The Spectrum of Cardiac Manifestations in Coronavirus Disease 2019 (COVID-19) - a Systematic Echocardiographic Study. Circulation, 10.1161/ CIRCULATIONAHA.120.047971. Advance online publication. https://doi. org/10.1161/CIRCULATIONAHA.120.047971

15. Sud, K., Vogel, B., Bohra, C., Garg, V., Talebi, S., Lerakis, S., Narula, J., \& Argulian, E. (2020). Echocardiographic Findings in Patients with COVID-19 with Significant Myocardial Injury. Journal of the American Society of Echocardiography: official publication of the American Society of Echocardiography, S0894-7317(20)30367-9. Advance online publication. https://doi.org/10.1016/j.echo.2020.05.030

16. Marc R Dweck, Anda Bularga, Rebecca T Hahn, Rong Bing, Kuan Ken Lee, Andrew R Chapman, Audrey White, Giovanni Di Salvo, Leyla Elif Sade, Keith Pearce, David E Newby, Bogdan A Popescu, ErwanDonal, Bernard Cosyns, Thor Edvardsen, Nicholas L Mills, Kristina Haugaa. Global evaluation of echocardiography in patients with COVID-19, European Heart Journal - Cardiovascular Imaging, jeaa178, https://doi. org/10.1093/ehjci/jeaa178 